\title{
Effects of nutrition counselling and unconditional cash transfer on child growth and family food security in internally displaced person camps in Somalia - A quasi-experimental study
}

Mohamed Kalid ( $\square$ mki@du.se )

Dalarna University

Renée Flacking

Dalarna University

Munshi Sulaiman

BRAC International

Fatumo Osman

Dalarna University

Research Article

Keywords: counselling, cash transfer, humanitarian setting, IDP, nutrition, underweight, wasting

Posted Date: February 7th, 2022

DOI: https://doi.org/10.21203/rs.3.rs-1311760/v1

License: (c) (1) This work is licensed under a Creative Commons Attribution 4.0 International License. Read Full License 


\section{Abstract}

\section{Background:}

The effects of nutrition counselling (NC) and unconditional cash transfer (UCT) in improving growth in children under five and household food security are poorly understood in humanitarian settings. The aim of this study was to evaluate the effects of NC and NC combined with unconditional cash transfer (NC+UCT) on children's growth and food security in Somalia.

\section{Methods:}

The study was performed with a quasi-experimental design in two districts in the Banadir region of Somalia. The study used twostage stratified sampling. Caregivers $(n=255)$ of mildly to moderately malnourished children aged 6 to 59 months old $(n=184)$ were randomized to the NC, NC+UCT and control groups. The interventions consisted of weekly NC for three months alone or in combination with UCT. The primary outcome variables of the study were indicators of children's nutrition, i.e., wasting. The secondary outcome variables were indicators of underweight, stunting, and food security, i.e., dietary diversity, household hunger scale and food consumption scores. Data were collected at baseline and 11 months after programme implementation. Difference-in-differences analysis was used to estimate the effect of the interventions.

\section{Results:}

Our study did not find any significant impact on child wasting (aOR: $0.81,95 \% \mathrm{Cl}: 0.26-2.56, p=0.722$ ), underweight (aOR: 1.29, $95 \% \mathrm{Cl}: 0.40-3.48, p=0.603$ ), or stunting (aOR: $0.84,95 \% \mathrm{Cl}: 0.29-2.46, p=0.764$ ) compared to the control group. Similarly, in the NC+UCT group, we did not find any significant reduction in wasting (aOR: 0.79, 95\% Cl: 0.26-2.36, $p=0.669$ ), underweight (aOR: $0.88,95 \% \mathrm{Cl}: 0.33-2.35, p=0.806$ ), or stunting (aOR: $1.51,95 \% \mathrm{Cl}: 0.55-4.20, p=0.426$ ) compared to the control group. No intervention effect was observed on food security outcomes, child dietary diversity scores, minimum child dietary diversity ( $\geq 4$ food groups) or household expenses (Table 3).

\section{Conclusion:}

NC, alone or in combination with UCT, did not impact children's growth or household food security. A culturally tailored NC programme over a longer period and larger, regular, and predictable transfers might result in a significant reduction in malnutrition and food insecurity.

\section{Trial registration}

The evaluation was registered on the RIDIE registry (RIDIE-STUDY-ID-5a1264bdb207a) on 11/19/2017.

\section{Background}

Malnourished children in Sub-Saharan Africa account for one-third of all undernourished children globally; approximately $39 \%$ of children are stunted, $10 \%$ wasted, and $25 \%$ underweight [1-3]. The rate of malnutrition across Somalia is alarming and remains among the worst in the world. Approximately 1.2 million children under five are acutely malnourished in Somalia, including 232,000 who suffer from severe acute malnutrition [4]. Malnutrition is a major risk factor in children under five and is associated with a higher disease burden and increased levels of mortality [5].

Malnutrition has been shown to be multifactorial, and no single programme implemented in isolation is likely to be sufficient to sustain a significant reduction in undernutrition [6]. One of the most frequently used interventions to address malnutrition in a humanitarian setting is cash transfer. Usually, cash transfers are direct payments, often from governments or humanitarian agencies, made to eligible groups of people. Cash transfers are grouped into three main categories: unconditional cash transfer (UCT), which is a cash transfer made without any conditions that the recipient must meet; conditional cash transfer, which is made on the condition that the recipient meets specified criteria such as school attendance or receiving vaccinations; and labelled 
cash transfer, in which funds are indicated, or "labelled" for specific purposes, but the conditions are not enforced [7]. A recent review of the impacts of cash transfer showed that cash transfers did not necessarily improve child nutrition [8]; only three out of 14 studies showed a significant positive impact on the weight-for-age Z score (WAZ, i.e., underweight) and weight-for-height $Z$ score (WHZ, i.e., wasting). However, only a few such studies have been conducted in humanitarian settings and among internally displaced persons (IDPs) [9]. Food security is of outmost importance for optimal growth and has been defined as when a person has "access to sufficient, safe, nutritious food to maintain a healthy and active life" at all times [10]. Different studies have shown positive outcomes of cash transfer programs on food security $[11,12]$, but the evidence regarding the impact on child nutrition is mixed and inconclusive, particularly in Sub-Saharan Africa.

There have been a number of initiatives called "cash plus" that include additional components such as counselling on nutrition and infant and young child feeding during emergencies to achieve a greater effect on child nutrition [13]. Counselling is mainly aimed at promoting and/or strengthening caregivers' knowledge and practices regarding children's health and nutrition. It has been suggested that the promotion of breastfeeding, behaviour change communication to improve complementary feeding, zinc supplementation, vitamin A fortification, handwashing and severe malnutrition treatment are effective strategies to reduce child undernutrition [14]. The existing nutrition education counselling program in Somalia for preventing malnutrition involves training community workers, who then counsel caregivers regarding the feeding of children [15].

Cash transfer programs have become more common in Somalia over the past decade with the influx of local displacements, notably in the southern and central regions of the country. Most of the cash transfer programs have been short-term projects designed principally to address basic needs in humanitarian settings, are purely donor-led and target poor households. No previous studies have evaluated the impact of the provision of NC with and without cash transfer in Somalia. This study aimed to evaluate the effect of NC and UCT on children's growth and families' food security in IDP camps in Somalia.

\section{Methods And Design}

This study had a quasi-experimental design with two intervention arms and one control arm: NC with or without UCT. The effectiveness was assessed by measuring children's growth and families' food security pre- (baseline, July 2017) and postintervention (follow-up, February 2019).

\section{Setting}

The study was conducted in six IDP camps in two districts, Dayniile and Dharkanley, that host the majority of IDPs in the Banadir region of Somalia [16]. Those who live in these IDP camps are the most vulnerable groups and are often subject to arbitrary evictions by the government, as well as to evictions by landowners. IDP housing is unregulated and has no formal status that is monitored by the government. Instead, they are managed by local managers known as "gatekeepers". These gatekeepers act as brokers between IDPs, local authorities and nongovernmental organizations (NGOs). They offer IDPs plots of land in a settlement on which to live [17]. These districts were intentionally selected because they are areas with intervention programmes supported by an international NGO. At the beginning of the study period, in 2017, droughts ravaged Somalia, which left more than 6 million people or nearly half of the country's population displaced. Many members of the displaced population faced clean water and food shortages, which also brought cholera, diarrhoea and the worst measles outbreak in years [18].

\section{Sample size and power calculation}


The primary outcome for this study was the change in $\mathrm{WHZ}$ for individual children. Prior to implementation of the baseline survey, we conducted power calculations. We used the previous SMART Survey to estimate the WHZ. At the study design stage, we planned to enrol 400 children in each of the three groups (NC, NC+UCT, and control). An initial power calculation was performed to capture a minimum detectable effect of 0.08 in $\mathrm{WHZ}$ after accounting for an attrition rate of approximately $15 \%$. However, the study failed to enrol the target numbers. With the actual number of observations included in the study, i.e., 46 children in the NC group, 48 children in the NC+UCT group and 90 children in the control group, the minimum detectable effect size was a change of 0.18 in $\mathrm{WHZ}$ at $90 \%$ power when comparing any of the two intervention groups with the control group.

\section{Participants}

Caregivers who had the responsibility for one or more children aged 6-59 months were identified through a list of target beneficiaries supported by the NGO. The caregivers were mainly mothers but also included grandmothers or female guardians. The inclusion criteria were as follows: children aged six months up to five years who had mild or moderate malnutrition. Children with severe acute malnutrition ( $\mathrm{WHZ}<-3$ ) and apparent health problems were excluded and referred to the nearest health facility for further screening and treatment.

The study was approved by the Research and Ethics Review Committee of the Federal Ministry of Health (approval no. MoH \& HS/DGO/0129). Participants were provided detailed explanations about the study objectives and issues related to data collection, and written consent was obtained before commencing the study.

\section{Interventions}

The intervention consisted of NC alone or in combination with UCT (NC+UCT) on infant and young child feeding (IYCF) was provided to both intervention groups for three months (Aug-Oct 2017). The NC sessions were based on the UNICEF/WHO IYCF guidelines [19], and the topics covered are listed in Table 1. Participants received NC during one-to-two hour weekly NC sessions for 12 weeks. Each counselling session was attended by 20-22 caregivers. Eight trained community nutrition volunteers (CNVs) provided all of the sessions. The CNVs had undergone training provided by Save the Children and had previously conducted counselling sessions and nutrition assessments. A small monthly stipend was provided to the CNVs to use for transportation and calls to caregivers (e.g., when inviting caregivers to the counselling sessions). The counselling sessions were conducted at health facilities. Before every session, caregivers were asked to share their experiences and strategies that helped them to improve their household nutrition practices. Caregivers were encouraged to share information and provide support to each other throughout the sessions. The CNVs guided the sessions and discussions and provided information from the IYCF manual to ensure the quality of the information discussed. No monetary incentives were provided to the caregivers for their participation in the weekly sessions.

UCTs were provided, in addition to the NC, to one of the two intervention groups. The UCT involved a cash transfer of $\$ 40$ per month for 3 months through mobile phones with registered Simcards provided by Save the Children. The cash transfers were provided to parents within one month after the NC intervention had been completed.

\section{Data collection}

The baseline survey was collected in July 2017 and included 709 caregivers with 2,836 children. Twelve weeks after the NC intervention was completed and 11 months after the last cash transfer in the NC+UCT group, follow-up data was collected from

Page 4/17 
Data were collected by nine data collectors trained by Save the Children. They were all professional data collectors with several years of experience in data gathering for periodic monitoring and research projects. They received two days of refresher training from the first author in Mogadishu, Somalia, before starting data collection for both the baseline and follow-up surveys. The training focused on administering the study questionnaire, mobile data collection and how to conduct naturalistic observation. The data collectors conducted interviews at participants' residences. While the data collectors filled out the questionnaires using tablets, the CNVs took anthropometric measurements. The questionnaire used for data collection included questions on households' socioeconomic status and was complemented with observations (checklist) and questions about participants' household assets. Socioeconomic status was calculated based on a composite measure of household assets and amenities, such as the number of bedrooms, construction materials of the main house, ownership of household durable goods, type of household toilet used, and source of drinking water.

\section{Primary and secondary outcomes measures}

The primary outcome variable was WHZ (wasting) in children under five. We expected an intervention effect on acute rather than chronic malnutrition. Child weight was measured to the nearest $100 \mathrm{~g}$ using a digital scale (Seca, Hamburg, Germany). The length of children $<24$ months of age was measured to the nearest $0.1 \mathrm{~cm}$ with a length board (Seca), and the height of children $\geq 24$ months was measured to the nearest $0.1 \mathrm{~cm}$ with a portable stadiometer (Seca). We calculated $\mathrm{z}$ scores using the WHO child growth charts [20]. A mean WHZ >-0.40 is acceptable, and values between -0.40 and -0.69 are at the alert level in a humanitarian programming context. Values ranging from $>-0.70$ and -1.00 are either serious or critical levels of malnutrition.

Data quality checks and standardization for the anthropometry measurements obtained with automatic analysis were performed using the Emergency Nutrition Assessment for Standardized Monitoring and Assessment of Relief and Transitions (ENA for SMART) [21].

The secondary outcomes were the WAZ (underweight), the HAZ (stunting), and household food security indicators such as the household and child dietary diversity scores, household food consumption score, household hunger scale, minimum child dietary diversity score and household expenses. Food security status was measured from a set of questions that captured the domains of food access described in the Radimer framework [22]. To determine household food security, dietary diversity data were collected based on 24-hour recall. This indicator is based on eight food groups with 13 categories of food. The categories were cereals; roots and tubers; vegetables; fruits; meat, poultry and offal; eggs; fish and seafood; pulses/legumes/nuts; milk and milk products; oil/fat; sugar/honey; and miscellaneous [23]. Each group of foods had a binary outcome equal to one if a household member consumed the food during the 24 hours preceding the survey and zero otherwise. The score was calculated by summing the scores across the eight food groups, and it ranged from zero to eight.

\section{Randomization}

To reduce heterogeneity, we excluded IDP camps that had previously received similar interventions. We identified the targeted IDP camps based on a nutrition intervention programme that was implemented by Save the Children. Eligible caregivers and their children were randomized to one of the three arms with a uniform treatment allocation ratio: NC, NC+UCT and control. Stratification was performed to ensure an equal number of caregivers was assigned to each CNV delivering NC. STATA software was used to generate the random allocation sequence. Randomization was done at Save the Children's office, and the procedures and group assignments were inaccessible to the enumerators. The nature of the intervention precluded the masking of the treatments. 


\section{Statistical analysis}

Both descriptive and inferential statistics were used for analysis. Frequencies and percentages were computed to describe the sociodemographic characteristics of the study sample.

Principal component analysis (PCA) was used to determine the socioeconomic status of respondents using the sociodemographic data on the households. PCA reduced the multidimensional nature of the data to a single score that was categorized into three groups: low, middle and upper [24]. An intention-to-treat (ITT) analysis was performed regardless of NC session attendance. Difference-in-differences (DiD) estimates were run using regression models to calculate differences in outcomes between the intervention and control groups for each indicator at baseline and follow-up. To obtain the WHZ, WAZ and HAZ, the ZSCORE06 command in STATA was used. In addition to the Z scores, we generated a composite index of anthropometric failure (CIAF), which was coded as 1 if a child was wasted, stunted, underweight or any combination of these and 0 if they were not wasted, stunted or underweight [25]. The CIAF provided a more global measure of undernutrition. To measure food security indicators such as the dietary diversity score, food consumption score, and household hunger scale, a methodology recommended by the Emergency Food Security Assessment Handbook was used [26]. This methodology is based on the Food and Nutrition Security Conceptual Framework, which considers food availability, food access and utilization as core pillars of food security [27]. To measure the effects of the interventions, we included an intervention interaction term with a follow-up dummy in the model. Significance was defined as $p<0.05$. Data were analysed using STATA version 15 (Stata/SE 15.1 Stata Corporation, College Station, TX, USA).

\section{Results}

A total of 255 caregivers with 184 children were analysed (see the consort flow chart, Figure 1). The demographic characteristics of the population are presented in Table 2. There were no significant differences in wasting, underweight and stunting or among other food security indicators observed between the NC, NC+UCT and control groups. Out of the 12 sessions of NC, 66\% $(n=85)$ of the caregivers attended all sessions, $26 \%(n=33)$ attended 9-10 sessions, and information was lacking for 9 caregivers. All caregivers in the NC+UCT group received their cash transfer.

\section{Growth outcomes in children}

In the NC intervention group, we did not find any significant impact on wasting (aOR: $0.81,95 \% \mathrm{Cl}: 0.26-2.56, p=0.722$ ), underweight (aOR: $1.29,95 \% \mathrm{Cl}: 0.40-3.48, p=0.603$ ), or stunting (aOR: $0.84,95 \% \mathrm{Cl}: 0.29-2.46, p=0.764)$ compared to the control group. Similarly, in the NC+UCT group, we did not find any significant reduction in wasting (aOR: $0.79,95 \%$ Cl: $0.26-2.36$, $p=0.669$ ), underweight (aOR: $0.88,95 \% \mathrm{Cl}: 0.33-2.35, p=0.806)$, or stunting (aOR: $1.51,95 \% \mathrm{Cl}: 0.55-4.20, p=0.426)$ compared to the control group. Using a CIAF (being wasted, stunted, underweight or any combination of these), this study found no significant change in either intervention arm [25]. Similarly, no intervention effect was observed on the child dietary diversity score, minimum child dietary diversity ( $\geq 4$ food groups) or household expenses (Table 3 ).

Additional sensitivity analyses on WHZ, WAZ and HAZ to check for the presence of intervention effects on anthropometry were conducted. The results of these analyses are presented in Supplemental Table 1, and no intervention effect was observed for any of the three anthropometric $z$ scores.

\section{Food security and household expenses}

The data in Table 4 present the food security characteristics of the intervention and control groups. At baseline, caregivers in all three groups reported consumption of at least 7 food groups in the past 24 hours. There were no significant differences between baseline and follow-up in terms of dietary diversity score, household hunger scale score or household food consumption score in 
any of the groups (Table 4). Caregivers were also asked about expenses related to household food, water, fuel for food cooking, health and education, and no group showed a significant difference between baseline and follow-up.

\section{Discussion}

This is the first study to evaluate the impact of $\mathrm{NC}$ alone or in combination with UCT on caregivers of children with mild and moderate malnutrition. The findings from this study revealed that there were no statistically significant improvements in nutrition indicators such as wasting, stunting and underweight, measured in terms of WHZ, HAZ and WAZ, in the NC or NC+UCT group compared to the control group. Similarly, we did not detect statistically significant improvements in children's dietary diversity scores or other household food security indicators, such as household dietary diversity, household hunger scale score, household food consumption score and household expenses for children's health, food, water and education.

The overall lack of statistically significant improvements in growth and food security indicators is likely due to the poor socioeconomic and feeding practices among the target beneficiaries. Moreover, NC that is not individualized and adapted to each mother-child pair after a thorough analysis of the child's situation might not render positive results. The fact that our counselling was at the group level and not personalized and adapted to the socioeconomic situation of each woman likely contributed to the negative results [28].

Evidence has shown linkages between poverty and child malnutrition and resulted in two distinctive outcomes: 1) to ensure health for all, many countries have prioritized nutrition and developed minimum standards for their citizens; and 2) to develop human capital, the nutrition and wellbeing of the communities is scaled up through cash transfer programs in target communities. Therefore, this study addresses gaps in the literature. Moreover, several studies have shown that it is possible to improve children's health and nutrition through educational intervention by trained health workers as a part of routine preventive services [29-31].

Our study sought to understand the impact of $\mathrm{NC}$ alone on child growth. The lack of a significant reduction in wasting and underweight in our study was an unexpected finding but could be explained by the high mobility of IDPs, limited social services and high rate of loss to follow-up [32]. However, our findings are inconsistent with previous studies on the effectiveness of NC for caregivers in improving children's anthropometric measurements, which reported significant improvements in children's nutritional status [33-35]. Systematic reviews of NC topics such as breastfeeding promotion and complementary feeding education have suggested small to moderate effects on children's nutritional status depending on the background level of food security [36, 37]. However, these results confirm that interventions to improve IYCF have only modest effects on children's nutritional status if not supplemented with additional food, micronutrients and other interventions that can improve children's diets and women's health and nutrition in the prenatal period [38]. Additionally, data from other impact evaluation studies found that wasting and stunting cases are attributable to foetal growth restrictions, and they have highlighted the need to implement interventions before and during pregnancy [39-42].

The link between UCT and nutrition is also well researched and has been documented in several studies [43-45]. One potential reason for our nonsignificant finding could be that the cash transfer dispersed to the caregivers may not have been sufficiently large to detect improvements. On the other hand, it has been shown that when participants were offered a large amount of money for a longer period, no improvement was detected in children's nutritional status [46]. In a systematic review conducted by the Overseas Development Institute, the impact of cash transfer on child nutrition was examined [47]. Out of the five studies addressing the effect of cash transfer on child wasting, only one instance of conditional cash transfer (CCT) was found to result in a statistically significant reduction in wasting (13\%) among children aged 12-24 months. Similarly, the review showed a limited impact of cash transfer on underweight children, with only one instance of CCT in the eight studies reporting an overall effect of cash transfer on this indicator of $6.2 \%$. These findings suggest that only CCT had an effect on child malnutrition, and none of the UCTs had any measurable impact. Furthermore, in the same systematic review, the impact of cash transfer on food security 
indicators showed that out of the 12 studies examined, seven were found to have had at least one statistically significant improvement in dietary diversity [47]. Nonetheless, these results should be interpreted in light of the content and context of each intervention.

One possible explanation for our intervention not showing any improvements in children's growth is that the intervention was implemented in different seasons. The baseline survey was conducted during the dry season (Hagaa, July 2017), and the followup was conducted during the dry season (Feb 2019). Such seasons have the highest risk of famine. Changes in seasonal harvests always affect the food security situation [48]. In most humanitarian contexts, nutritional levels and food security conditions are generally worsened by little rain and extended drought over multiple seasons. Based on these pieces of evidence from other studies, future integrated interventions in humanitarian settings should assess the quality of training and supervision offered to caregivers, the amount of cash transfer, the mobility of IDPs, and the health and nutrition services offered to caregivers and children.

The strength of this study is that, to our knowledge, this is the first study to assess the impact of NC in combination with cash transfer on child nutrition in a population exposed to displacement. This study has also considerable limitations. First, the study lacked power and was not adequate to assess the nutritional impact or to study the relationship between changes in nutrition and food security. Second, the study was conducted in two distinct seasons, in which the intake of nutrients, WHZ and WAZ differed significantly, which adds to the external validity of the overall analysis. Third, half of the cash transfer recipients received cash transfer and NC late after randomization, and the data of these individuals was removed from the analyses. This reduced the original sample size and may have affected the study power. Fourth, overreporting of desirable dietary intake is a common occurrence in the assessment of feeding practices using recall techniques [35]. Finally, the quality of the training and supervision of CNVs is unclear, which affects the fidelity of the intervention.

\section{Conclusion}

Our results revealed that NC, alone or in combination with UCT, did not significantly improve children's growth or household food security. To improve the impact of NC, understanding the current existing capacity and community culture while providing NC during humanitarian emergencies not only helps us to identify current practices but also provides a foundation for making tailored plans to address any identified gaps. With regard to UCT, careful consideration should be given to the amount of money transferred, acknowledging household sizes and constitutions. Tailoring future interventions to deliver culturally relevant NC coupled with cash transfer could improve nutritional outcomes.

\section{Declarations}

\section{Ethics approval and consent to participate}

The Research and Ethics Review Committee of the Ministry of Health, South Central Somalia, provided ethical approval (D-nr: MoH\& HS/DGO/0129) for the study in 2017. The committee agreed that verbal consent from the participants was sufficient to gather data. Because children were involved in this study, information and consent were obtained from adult guardians.

\section{Consent for publication}

The verbal explanation and consent included receiving confirmation from the guardians that the data on the children could be published. 
The study datasets are available from the corresponding author on request.

\section{Competing interests}

The authors declare that they have no competing interests.

\section{Funding}

The study was funded by Global Affairs Canada and the Federal Foreign Office (FFO) - Berlin through Save the Children International, Somalia Country Office.

\section{Author's contributions}

MK and MS contributed to the design of the study. All authors have also contributed to the interpretation of the analysed data and writing of the manuscript. MK gathered the data together with local data collectors and CNVs under the supervision of MS. MK entered the data into the dataset and performed the analysis on the data under the supervision of MS, RK and FO. MK wrote the manuscript together with RK, FO, and MS. All authors read and approved the final manuscript.

\section{Acknowledgements}

We acknowledge the financial support from Save the Children International, Somalia Country Office, for funding this study. We also appreciate the support we received from REALM and the Child Poverty Sectors at Save the Children. Finally, we thank the study participants, data collectors and community nutrition volunteers, whose cooperation and voluntary participation made this study successful.

\section{Abbreviations}

WHZ: Weight-for-height Z score

WAZ: Weight-for-age Z score

DID: Difference-in-differences

WHO: World Health Organization

NC: Nutrition counselling

UCT: Unconditional cash transfer

IDP: Internally displaced person

CNV: Community nutrition volunteer

CIAF: Composite index of anthropometric failure

\section{References}

1. Aguayo VM, Badgaiyan N, Dzed L: Determinants of child wasting in Bhutan. Insights from nationally representative data. Public health nutrition 2017, 20(2):315-324. 
2. Black RE, Victora CG, Walker SP, Bhutta ZA, Christian P, De Onis M, Ezzati M, Grantham-McGregor S, Katz J, Martorell R: Maternal and child undernutrition and overweight in low-income and middle-income countries. The lancet 2013, 382(9890):427451.

3. Ahmadi D, Amarnani E, Sen A, Ebadi N, Cortbaoui P, Melgar-Quiñonez H: Determinants of child anthropometric indicators in Ethiopia. BMC public health 2018, 18(1):626.

4. UNICEF Somalia Humanitarian Situation Report \#3: 1-31 March 2018 [https://reliefweb.int/report/somalia/unicef-somaliahumanitarian-situation-report-3-1-31-march-2018]

5. UNICEF: Improving child nutrition: the achievable imperative for global progress. United Nations Childrens Fund. New York. 2013:1-14.

6. Akhade KS, Sankhe LR, Akarte SV: Magnitude of malnutrition among underfive children in urban slums of commercial capital of India and its multifactorial causation: A community-based study. Journal of family medicine and primary care 2019, 8(12):3865.

7. Sircar NR, Friedman EA: Financial security and public health: how basic income \& cash transfers can promote health. Global public health 2018, 13(12):1878-1888.

8. Battistin AMaF: A synthesis of the evidence around survival, education and protection in humanitarian and nonhumanitarian contexts. Save the Children International 2018.

9. Penny ME, Creed-Kanashiro HM, Robert RC, Narro MR, Caulfield LE, Black RE: Effectiveness of an educational intervention delivered through the health services to improve nutrition in young children: a cluster-randomised controlled trial. The Lancet 2005, 365(9474):1863-1872.

10. Napoli M, De Muro P, Mazziotta M: Towards a food insecurity Multidimensional Index (FIMI). Master in Human Development and Food Security 2011:1-72.

11. Attanasio 0, Mesnard A: The impact of a conditional cash transfer programme on consumption in Colombia. Fiscal studies 2006, 27(4):421-442.

12. Pega F, Liu SY, Walter S, Pabayo R, Saith R, Lhachimi SK: Unconditional cash transfers for reducing poverty and vulnerabilities: effect on use of health services and health outcomes in low- and middle-income countries. Cochrane Database of Systematic Reviews 2017(11).

13. Pega F, Liu SY, Walter S, Lhachimi SK: Unconditional cash transfers for assistance in humanitarian disasters: Effect on use of health services and health outcomes in low-and middle-income countries. Cochrane Database of Systematic Reviews 2015(9).

14. Bhutta ZA, Ahmed T, Black RE, Cousens S, Dewey K, Giugliani E, Haider BA, Kirkwood B, Morris SS, Sachdev H: What works? Interventions for maternal and child undernutrition and survival. The lancet 2008, 371(9610):417-440.

15. Kalid M, Osman F, Sulaiman M, Dykes F, Erlandsson K: Infant and young child nutritional status and their caregivers' feeding knowledge and hygiene practices in internally displaced person camps, Somalia. BMC nutrition 2019, 5(1):1-11.

16. Majid N, McDowell S: Hidden dimensions of the Somalia famine. Global Food Security 2012, 1(1):36-42.

17. Bryld E, Kamau C, Mohamoud MA: Using an adaptive approach to making gatekeepers accountable to internally displaced persons in Mogadishu, Somalia. Development in practice 2020:1-12.

18. Yarnell M, Thomas A: SOMALIS FORCED TO FLEE DROUGHT AND NEAR FAMINE CONDITIONS. 2017.

19. World Health Organization \&UNICEF: Infant young child feeding counselling: An integrated course. 2006 http://www. who. int/nutrition/publications/infantfeeding/9789241594745/en. Accessed August 2014, 11. 
20. WHO: WHO child growth standards based on length/height, weight and age. Acta Paediatr Supp/2006, 450:76-85.

21. ENA for SMART.: Software for Emergency Nutrition Assessment [Internet]. In.; 2011.

22. Radimer KL, Olson CM, Campbell CC: Development of indicators to assess hunger. The Journal of nutrition 1990, 120(suppl_11):1544-1548.

23. Swindale A, Bilinsky P: Household dietary diversity score (HDDS) for measurement of household food access: indicator guide. Washington, DC: Food and Nutrition Technical Assistance Project, Academy for Educational Development 2006.

24. Filmer D, Pritchett LH: Estimating wealth effects without expenditure data-or tears: an application to educational enrollments in states of India. Demography 2001, 38(1):115-132.

25. Nandy S, Svedberg P: The Composite Index of Anthropometric Failure (CIAF): An alternative indicator for malnutrition in young children. In: Handbook of anthropometry. edn.: Springer; 2012: 127-137.

26. Swindale A, Bilinsky P: Development of a universally applicable household food insecurity measurement tool: process, current status, and outstanding issues. The Journal of nutrition 2006, 136(5):1449S-1452S.

27. Programme WF: Comprehensive Food Security \& Vulnerability Analysis (CFSVA). In.; 2009.

28. Nikièma L, Huybregts L, Martin-Prevel Y, Donnen P, Lanou H, Grosemans J, Offoh P, Dramaix-Wilmet M, Sondo B, Roberfroid $D$ et al: Effectiveness of facility-based personalized maternal nutrition counseling in improving child growth and morbidity up to 18 months: A cluster-randomized controlled trial in rural Burkina Faso. PloS one 2017, 12(5):e0177839-e0177839.

29. Sunguya BF, Poudel KC, Mlunde LB, Urassa DP, Yasuoka J, Jimba M: Nutrition training improves health workers' nutrition knowledge and competence to manage child undernutrition: a systematic review. Frontiers in public health 2013, 1:37.

30. Sunguya BF, Poudel KC, Mlunde LB, Shakya P, Urassa DP, Jimba M, Yasuoka J: Effectiveness of nutrition training of health workers toward improving caregivers' feeding practices for children aged six months to two years: a systematic review. Nutrition journal 2013, 12(1):1-14.

31. Imdad A, Yakoob MY, Bhutta ZA: Impact of maternal education about complementary feeding and provision of complementary foods on child growth in developing countries. BMC public health 2011, 11(3):1-14.

32. Elisaria E, Mrema J, Bogale T, Segafredo G, Festo C: Effectiveness of integrated nutrition interventions on childhood stunting: a quasi-experimental evaluation design. BMC Nutrition 2021, 7(1):17.

33. Guldan GS, Fan H-C, Ma X, Ni Z-Z, Xiang X, Tang M-Z: Culturally appropriate nutrition education improves infant feeding and growth in rural Sichuan, China. The Journal of nutrition 2000, 130(5):1204-1211.

34. Shi L, Zhang J, Wang Y, Caulfield LE, Guyer B: Effectiveness of an educational intervention on complementary feeding practices and growth in rural China: a cluster randomised controlled trial. Public health nutrition 2010, 13(4):556-565.

35. Bhandari N, Mazumder S, Bahl R, Martines J, Black R, Bhan M: other members of the Infant Feeding Study Group: An educational intervention to promote appropriate complementary feeding practices and physical growth in infants and young children in rural Haryana, India. J Nutr 2004, 134:2342-2348.

36. Giugliani ER, Horta BL, Loret de Mola C, Lisboa BO, Victora CG: Effect of breastfeeding promotion interventions on child growth: a systematic review and meta-analysis. Acta Paediatrica 2015, 104:20-29.

37. Renzaho AMN, Chen W, Rijal S, Dahal P, Chikazaza IR, Dhakal T, Chitekwe S: The impact of unconditional child cash grant on child malnutrition and its immediate and underlying causes in five districts of the Karnali Zone, Nepal - A trend analysis.

Archives of Public Health 2019, 77(1):24. 
38. Dewey KG: Reducing stunting by improving maternal, infant and young child nutrition in regions such as South Asia: evidence, challenges and opportunities. Maternal \& child nutrition 2016, 12:27-38.

39. McDonald CM, Olofin I, Flaxman S, Fawzi WW, Spiegelman D, Caulfield LE, Black RE, Ezzati M, Danaei G, Study NIM: The effect of multiple anthropometric deficits on child mortality: meta-analysis of individual data in 10 prospective studies from developing countries. The American journal of clinical nutrition 2013, 97(4):896-901.

40. Caulfield LE, de Onis M, Blössner M, Black RE: Undernutrition as an underlying cause of child deaths associated with diarrhea, pneumonia, malaria, and measles. The American journal of clinical nutrition 2004, 80(1):193-198.

41. Christian P, Lee SE, Donahue Angel M, Adair LS, Arifeen SE, Ashorn P, Barros FC, Fall CH, Fawzi WW, Hao W: Risk of childhood undernutrition related to small-for-gestational age and preterm birth in low-and middle-income countries. International journal of epidemiology 2013, 42(5):1340-1355.

42. Danaei G, Andrews KG, Sudfeld CR, Fink G, McCoy DC, Peet E, Sania A, Smith Fawzi MC, Ezzati M, Fawzi WW: Risk factors for childhood stunting in 137 developing countries: a comparative risk assessment analysis at global, regional, and country levels. PLoS medicine 2016, 13(11):e1002164.

43. Renzaho AM, Chen W, Rijal S, Dahal P, Chikazaza IR, Dhakal T, Chitekwe S: The impact of unconditional child cash grant on child malnutrition and its immediate and underlying causes in five districts of the Karnali Zone, Nepal-A trend analysis. Archives of Public Health 2019, 77(1):1-18.

44. Seal A, Dolan C, Trenouth L: REFANI synthesis report. In.: Research on Food Assistance for Nutritional Impact Consortium London; 2017.

5. Seidenfeld D, Handa S, Tembo G, Michelo S, Harland Scott C, Prencipe L: The impact of an unconditional cash transfer on food security and nutrition: the Zambia Child Grant Programme. 2014.

46. Grijalva-Eternod CS, Jelle M, Haghparast-Bidgoli H, Colbourn T, Golden K, King S, Cox CL, Morrison J, Skordis-Worrall J, Fottrell E: A cash-based intervention and the risk of acute malnutrition in children aged 6-59 months living in internally displaced persons camps in Mogadishu, Somalia: A non-randomised cluster trial. PLoS medicine 2018, 15(10):e1002684.

47. Bastagli F, Hagen-Zanker J, Harman L, Barca V, Sturge G, Schmidt T, Pellerano L: Cash transfers: what does the evidence say. A rigorous review of programme impact and the role of design and implementation features London: ODI 2016, 1(7).

48. Hillbruner C, Moloney G: When early warning is not enough-Lessons learned from the 2011 Somalia Famine. Global Food Security 2012, 1(1):20-28.

\section{Tables}

Table 1. Training topics covered in 12 Sessions. 


\section{Topics covered}

- Early initiation

- Exclusive breastfeeding

- Breastfeeding and benefits

- Introduction of complementary feeding

- Continuous breastfeeding

- Dietary diversity and frequency

- Frequency of feeding for children aged 6-8 months

- Frequency of feeding for children aged 9-23 months

- Refusal to eat

- Sleep at night

- Diarrhoea/illness

- Treatment of water

- Handwashing

- Water and faeces management

- Bottle feeding and risks

- Vitamin A/deworming/full immunization

Table 2. Baseline characteristics of the study arms 


\begin{tabular}{|c|c|c|c|c|}
\hline \multicolumn{2}{|l|}{ Caregiver Variables } & \multicolumn{3}{|l|}{ Baseline } \\
\hline & & \multirow{2}{*}{$\begin{array}{l}\mathrm{NC} \\
(\mathrm{N}=87)\end{array}$} & $\begin{array}{l}\mathrm{NC}+\mathrm{UCT} \\
(\mathrm{N}=88)\end{array}$ & \multirow{2}{*}{$\begin{array}{l}\text { Control } \\
(\mathrm{N}=175)\end{array}$} \\
\hline \multirow{3}{*}{ Districts } & & & & \\
\hline & Dayniile, n (\%) & $22(25.3)$ & $22(25)$ & $44(25.1)$ \\
\hline & Dharkanley, n (\%) & $65(74.7)$ & $66(75.0)$ & $131(74.9)$ \\
\hline \multirow[t]{4}{*}{ Caregiver age, $\mathrm{n}(\%)$} & $15-19$ & $3(3.5)$ & $6(6.8)$ & $16(9.1)$ \\
\hline & $20-29$ & $37(42.5)$ & $64(72.7)$ & $89(50.9)$ \\
\hline & $30-39$ & $41(47.1)$ & $16(18.2)$ & $60(34.3)$ \\
\hline & $40 \geq$ & $6(6.9)$ & $2(2.3)$ & $10(5.7)$ \\
\hline \multicolumn{2}{|l|}{ Married caregivers, n (\%) } & $84(97.0)$ & $86(97.7)$ & $155(88.6)$ \\
\hline \multicolumn{2}{|l|}{ Age at first marriage, (mean $\pm s d)$} & $16.0 \pm 1.8$ & $16 \pm 2.4$ & $16.0 \pm 2.2$ \\
\hline \multicolumn{2}{|l|}{ Age at first childbirth, (mean $\pm s d)$} & $17.0 \pm 1.8$ & $18.0 \pm 2.4$ & $17.0 \pm 2.1$ \\
\hline \multirow[t]{3}{*}{ Socioeconomic status of household, $\mathrm{n}(\%)$} & Low & $28(32)$ & $26(30)$ & $42(24)$ \\
\hline & Middle & $25(28.7)$ & $22(25)$ & $45(25.7)$ \\
\hline & Upper & $34(39.1)$ & $40(45.5)$ & $88(50.3)$ \\
\hline \multicolumn{2}{|l|}{ Average number of children, (mean $\pm \mathrm{sd}$ ) } & $7 \pm 3.5$ & $5 \pm 3.1$ & $5 \pm 3.1$ \\
\hline \multicolumn{2}{|c|}{ Caregivers attended ANC during the last pregnancy ${ }^{\mathrm{a}}, \mathrm{n}(\%)$} & $27(79.4)$ & $32(94.1)$ & $56(93.3)$ \\
\hline \multicolumn{2}{|c|}{ Month visited at ANC during the first pregnancy ${ }^{a}$, (mean $\left.\pm s d\right)$} & $5 \pm 1.6$ & $4 \pm 1.5$ & $4 \pm 1.5$ \\
\hline \multirow{2}{*}{\multicolumn{2}{|c|}{ Child Variables }} & NC & NC+UCT & Control \\
\hline & & $(N=148)$ & $(N=116)$ & $(N=260)$ \\
\hline \multicolumn{2}{|l|}{ Sex of child is female, $\mathrm{n}(\%)$} & $24(52.2)$ & $25(52.1)$ & $50(55.6)$ \\
\hline \multicolumn{2}{|l|}{ Age of the child in months, (mean \pm sd) } & $34.7 \pm 15.9$ & $27 \pm 15.3$ & $29.7 \pm 14.9$ \\
\hline
\end{tabular}

a Number represents those who attended ANC

Table 3. Intervention effects on child growth and food security outcomes between baseline and follow-up. 


\begin{tabular}{|c|c|c|c|c|c|c|c|c|c|c|}
\hline \multirow[t]{2}{*}{$\begin{array}{l}\text { Indicator of } \\
\text { Interest }\end{array}$} & & NC & & $\mathrm{NC}+\mathrm{UCT}$ & & Control & $\begin{array}{l}\text { Effect of } \\
\text { NC vs. } \\
\text { Control }\end{array}$ & $p$ & $\begin{array}{l}\text { Effect of } \\
\text { NC+UCT } \\
\text { vs. } \\
\text { Control }\end{array}$ & $p$ \\
\hline & Baseline & $\begin{array}{l}\text { Follow- } \\
\text { up }\end{array}$ & Baseline & $\begin{array}{l}\text { Follow- } \\
\text { up }\end{array}$ & Baseline & $\begin{array}{l}\text { Follow- } \\
\text { up }\end{array}$ & $\begin{array}{l}\text { Adjusted } \\
\text { OR (95\% } \\
\mathrm{Cl})^{\mathrm{a}}\end{array}$ & & $\begin{array}{l}\text { Adjusted } \\
\text { OR (95\% } \\
\mathrm{Cl})^{\mathrm{a}}\end{array}$ & \\
\hline & $N=148$ & $N=46$ & $\mathrm{~N}=116$ & $N=48$ & $N=260$ & $N=90$ & & & & \\
\hline Wasting, n (\%) & $\begin{array}{l}18 \\
(12.2)\end{array}$ & $\begin{array}{l}7 \\
(15.2)\end{array}$ & $\begin{array}{l}18 \\
(15.5)\end{array}$ & $\begin{array}{l}9 \\
(18.7)\end{array}$ & $\begin{array}{l}31 \\
(11.9)\end{array}$ & $\begin{array}{l}16 \\
(17.8)\end{array}$ & $\begin{array}{l}0.81 \\
(0.26- \\
2.56)\end{array}$ & 0.722 & $\begin{array}{l}0.79 \\
(0.26- \\
2.36)\end{array}$ & 0.669 \\
\hline $\begin{array}{l}\text { Underweight, n } \\
\text { (\%) }\end{array}$ & $\begin{array}{l}44 \\
(29.7)\end{array}$ & $\begin{array}{l}21 \\
(45.7)\end{array}$ & $\begin{array}{l}42 \\
(36.2)\end{array}$ & $\begin{array}{l}22 \\
(45.8)\end{array}$ & $\begin{array}{l}91 \\
(35.00)\end{array}$ & $\begin{array}{l}43 \\
(47.8)\end{array}$ & $\begin{array}{l}1.29 \\
(0.40- \\
3.48)\end{array}$ & 0.603 & $\begin{array}{l}0.88 \\
(0.33- \\
2.35)\end{array}$ & 0.806 \\
\hline Stunting, n (\%) & $\begin{array}{l}25 \\
(16.9)\end{array}$ & $\begin{array}{l}10 \\
(21.7)\end{array}$ & $\begin{array}{l}20 \\
(17.2)\end{array}$ & $\begin{array}{l}16 \\
(33.3)\end{array}$ & $\begin{array}{l}44 \\
(16.9)\end{array}$ & $\begin{array}{l}22 \\
(24.4)\end{array}$ & $\begin{array}{l}0.84 \\
(0.29- \\
2.46)\end{array}$ & 0.764 & $\begin{array}{l}1.51 \\
(0.55- \\
4.20)\end{array}$ & 0.426 \\
\hline $\begin{array}{l}\text { Composite } \\
\text { index of } \\
\text { anthropometric } \\
\text { failure }^{\mathrm{b}}, \mathrm{n}(\%)\end{array}$ & $\begin{array}{l}62 \\
(41.9)\end{array}$ & $\begin{array}{l}28 \\
(60.8)\end{array}$ & $\begin{array}{l}58 \\
(50.0)\end{array}$ & $\begin{array}{l}32 \\
(66.7)\end{array}$ & $\begin{array}{l}124 \\
(47.7)\end{array}$ & $\begin{array}{l}57 \\
(63.3)\end{array}$ & $\begin{array}{l}1.21 \\
(0.45- \\
3.25)\end{array}$ & 0.701 & $\begin{array}{l}1.06 \\
(0.39- \\
2.87)\end{array}$ & 0.912 \\
\hline $\begin{array}{l}\text { Children's } \\
\text { minimum } \\
\text { dietary } \\
\text { diversity ( } \geq 4 \\
\text { food groups), n } \\
(\%)\end{array}$ & $\begin{array}{l}18 \\
(12.2)\end{array}$ & $\begin{array}{l}28 \\
(60.9)\end{array}$ & $9(7.8)$ & $\begin{array}{l}22 \\
(45.8)\end{array}$ & $\begin{array}{l}31 \\
(11.9)\end{array}$ & $\begin{array}{l}52 \\
(57.8)\end{array}$ & $\begin{array}{l}1.16 \\
(0.39- \\
3.48)\end{array}$ & 0.779 & $\begin{array}{l}1.01 \\
(0.31- \\
3.27)\end{array}$ & 0.988 \\
\hline $\begin{array}{l}\text { Child dietary } \\
\text { diversity score } \\
\text { (mean } \pm \text { sd) }\end{array}$ & $\begin{array}{l}3.3 \pm \\
1.2\end{array}$ & $\begin{array}{l}4.8 \pm \\
1.6\end{array}$ & $\begin{array}{l}2.9 \pm \\
1.3\end{array}$ & $\begin{array}{l}4.6 \pm \\
2.0\end{array}$ & $\begin{array}{l}3.2 \pm \\
1.4\end{array}$ & $\begin{array}{l}4.8 \pm \\
1.9\end{array}$ & $\begin{array}{l}-0.18 \\
(-0.90\end{array}$ & 0.612 & $\begin{array}{l}0.03 \\
(-0.78- \\
0.84)\end{array}$ & 0.951 \\
\hline
\end{tabular}

a Differences in wasting, underweight and stunting at follow-up, adjusted for baseline differences in anthropometry

$\mathrm{b}$ The composite index of anthropometric failure includes six categories of undernutrition: wasting only, wasting and underweight, wasting, stunting and underweight, stunting and underweight, stunting only, and underweight only. A child is considered to have anthropometric failure if they are either wasted, underweight or stunted or any combination of these.

Table 4. Intervention effects on the caregiver report-based dietary diversity score, household hunger scale score, household food consumption score and expenditure situation. 


\begin{tabular}{|c|c|c|c|c|c|c|c|c|c|c|}
\hline $\begin{array}{l}\text { Indicator of } \\
\text { Interest }\end{array}$ & NC & & NC+UCT & & Control & & $\begin{array}{l}\text { Effect of } \\
\text { NC vs. } \\
\text { Control }\end{array}$ & $p$ & $\begin{array}{l}\text { Effect of } \\
\text { NC+UCT } \\
\text { vs. } \\
\text { Control }\end{array}$ & $p$ \\
\hline & $\begin{array}{l}\text { Baseline } \\
N=87\end{array}$ & $\begin{array}{l}\text { Follow- } \\
\text { up } \\
N=66\end{array}$ & $\begin{array}{l}\text { Baseline } \\
N=88\end{array}$ & $\begin{array}{l}\text { Follow- } \\
\text { up } \\
\mathrm{N}=63\end{array}$ & $\begin{array}{l}\text { Baseline } \\
N=175\end{array}$ & $\begin{array}{l}\text { Follow- } \\
\text { up } \\
\mathrm{N}=126\end{array}$ & $\begin{array}{l}\text { Adjusted } \\
\text { coefficient } \\
(95 \% \mathrm{Cl})\end{array}$ & & $\begin{array}{l}\text { Adjusted } \\
\text { coefficient } \\
\text { (95\% Cl) }\end{array}$ & \\
\hline & Mean & Mean & Mean & Mean & Mean & Mean & & & & \\
\hline & $(95 \% \mathrm{Cl})$ & $\begin{array}{l}(95 \% \\
\mathrm{Cl})\end{array}$ & $(95 \% \mathrm{Cl})$ & $\begin{array}{l}(95 \% \\
\mathrm{Cl})\end{array}$ & $(95 \% \mathrm{Cl})$ & $\begin{array}{l}(95 \% \\
\mathrm{Cl})\end{array}$ & & & & \\
\hline $\begin{array}{l}\text { Household } \\
\text { dietary } \\
\text { diversity score } \\
\text { (12 food } \\
\text { groups) }\end{array}$ & $\begin{array}{l}6.9(6.6- \\
7.3)\end{array}$ & $\begin{array}{l}7.2 \\
(6.7- \\
7.7)\end{array}$ & $\begin{array}{l}6.8(6.5- \\
7.2)^{(6 .}\end{array}$ & $\begin{array}{l}7.4 \\
(7.1- \\
7.8)\end{array}$ & $\begin{array}{l}6.8(6.7- \\
7.0)\end{array}$ & $\begin{array}{l}7.4 \\
(7.1- \\
7.8)\end{array}$ & $\begin{array}{l}-0.3(-1.2- \\
0.4)\end{array}$ & 0.31 & $\begin{array}{l}-0.1(-0.8- \\
0.7)\end{array}$ & 0.90 \\
\hline $\begin{array}{l}\text { Household } \\
\text { hunger scale } \\
\text { score }\end{array}$ & $\begin{array}{l}3.3(3.1- \\
3.6)\end{array}$ & $\begin{array}{l}2.1 \\
(1.7- \\
2.5)\end{array}$ & $\begin{array}{l}3.3(3.1- \\
3.6)\end{array}$ & $\begin{array}{l}2.6 \\
(2.2- \\
3.0)\end{array}$ & $\begin{array}{l}3.5(3.3- \\
3.7)\end{array}$ & $\begin{array}{l}2.5 \\
(2.2- \\
2.8)\end{array}$ & $\begin{array}{l}-0.2(-0.9- \\
0.4)\end{array}$ & 0.37 & $\begin{array}{l}0.2(-0.3- \\
0.8)\end{array}$ & 0.55 \\
\hline $\begin{array}{l}\text { Household } \\
\text { food } \\
\text { consumption } \\
\text { score }\end{array}$ & $\begin{array}{l}10.5 \\
(9.7- \\
11.4)\end{array}$ & $\begin{array}{l}10.9 \\
(9.8- \\
12.0)\end{array}$ & $\begin{array}{l}10.0 \\
(9.4- \\
10.7)\end{array}$ & $\begin{array}{l}11.8 \\
(10.9- \\
12.7)\end{array}$ & $\begin{array}{l}10.8 \\
(10.3- \\
11.3)\end{array}$ & $\begin{array}{l}11.8 \\
(11.3- \\
15.5)\end{array}$ & $\begin{array}{l}-0.7(-2.2- \\
0.8)\end{array}$ & 0.35 & $\begin{array}{l}0.7(-0.7- \\
2.0)\end{array}$ & 0.31 \\
\hline \multicolumn{11}{|c|}{ Household Expenses ${ }^{a}$} \\
\hline Food & $\begin{array}{l}46 \\
(40.5- \\
51.0)\end{array}$ & $\begin{array}{l}46 \\
(40.3- \\
52.6)\end{array}$ & $\begin{array}{l}41 \\
(35.8- \\
46.5)\end{array}$ & $\begin{array}{l}43 \\
(39.2- \\
46.9)\end{array}$ & $\begin{array}{l}43 \\
(39.4- \\
47.3)\end{array}$ & $\begin{array}{l}39 \\
(36.7- \\
41.9)\end{array}$ & $\begin{array}{l}4.7(-3.7- \\
13.1)\end{array}$ & 0.27 & $\begin{array}{l}5.9(-1.9- \\
13.7)\end{array}$ & 0.14 \\
\hline Water & $\begin{array}{l}9(6.8- \\
10.3)\end{array}$ & $\begin{array}{l}6(4.8- \\
6.6)\end{array}$ & $\begin{array}{l}8(6.2- \\
9.2)\end{array}$ & $\begin{array}{l}6(4.5- \\
7.2)\end{array}$ & $\begin{array}{l}8(7.2- \\
9.6)\end{array}$ & $\begin{array}{l}5\left(4.3^{-}\right. \\
5.8)\end{array}$ & $\begin{array}{l}0.4(-1.7- \\
2.6)\end{array}$ & 0.69 & $\begin{array}{l}1.4(-0.7- \\
3.6)\end{array}$ & 0.18 \\
\hline $\begin{array}{l}\text { Fuel for } \\
\text { cooking }\end{array}$ & $\begin{array}{l}9(7.4- \\
10.8)\end{array}$ & $\begin{array}{l}9(7.0- \\
10.3)\end{array}$ & $\begin{array}{l}7(5.8- \\
8.4)\end{array}$ & $\begin{array}{l}7(6.4- \\
8.4)\end{array}$ & $\begin{array}{l}8(6.9- \\
8.8)\end{array}$ & $\begin{array}{l}7(6.5- \\
7.9)\end{array}$ & $\begin{array}{l}0.21(-2.3- \\
2.8)\end{array}$ & 0.86 & $\begin{array}{l}0.94(-0.9- \\
2.8)\end{array}$ & 0.34 \\
\hline Education & $\begin{array}{l}4(2.2- \\
5.2)\end{array}$ & $\begin{array}{l}5(3.1- \\
6.9)\end{array}$ & $\begin{array}{l}2(0.5- \\
2.8)\end{array}$ & $\begin{array}{l}2(0.7- \\
2.9)\end{array}$ & $\begin{array}{l}3(1.5- \\
3.9)\end{array}$ & $\begin{array}{l}4(2.7- \\
5.3)\end{array}$ & $\begin{array}{l}-0.1(-3.2- \\
3.1)\end{array}$ & 0.96 & $\begin{array}{l}-1.2(-3.7- \\
1.3)\end{array}$ & 0.34 \\
\hline $\begin{array}{l}\text { Health } \\
\text { expenses for } \\
\text { children under } \\
18\end{array}$ & $\begin{array}{l}4(2.5- \\
5.7)\end{array}$ & $\begin{array}{l}4(1.7- \\
7.3)\end{array}$ & $\begin{array}{l}3(1.4- \\
3.6)\end{array}$ & $\begin{array}{l}1(0.4- \\
2.2)\end{array}$ & $\begin{array}{l}2(1.4- \\
3.0)\end{array}$ & $\begin{array}{l}2(0.8- \\
2.3)\end{array}$ & $\begin{array}{l}0.3(-3.9- \\
4.4)\end{array}$ & 0.90 & $\begin{array}{l}-0.7(-2.6- \\
1.1)\end{array}$ & 0.41 \\
\hline $\begin{array}{l}\text { Health } \\
\text { expenses for } \\
\text { all members } \\
\text { over } 18\end{array}$ & $\begin{array}{l}4(2.3- \\
5.6)\end{array}$ & $\begin{array}{l}2(0.9- \\
3.6)\end{array}$ & $\begin{array}{l}3(1.8- \\
4.5)\end{array}$ & $\begin{array}{l}1 \\
(0.03- \\
1.3)\end{array}$ & $\begin{array}{l}3(1.7- \\
4.7)\end{array}$ & $\begin{array}{l}2(0.7- \\
2.2)\end{array}$ & $\begin{array}{l}-0.0(-2.6- \\
2.5)\end{array}$ & 0.98 & $\begin{array}{l}-0.8(-3.0- \\
1.4)\end{array}$ & 0.47 \\
\hline
\end{tabular}

${ }^{a}$ Amount in USD

Figures 


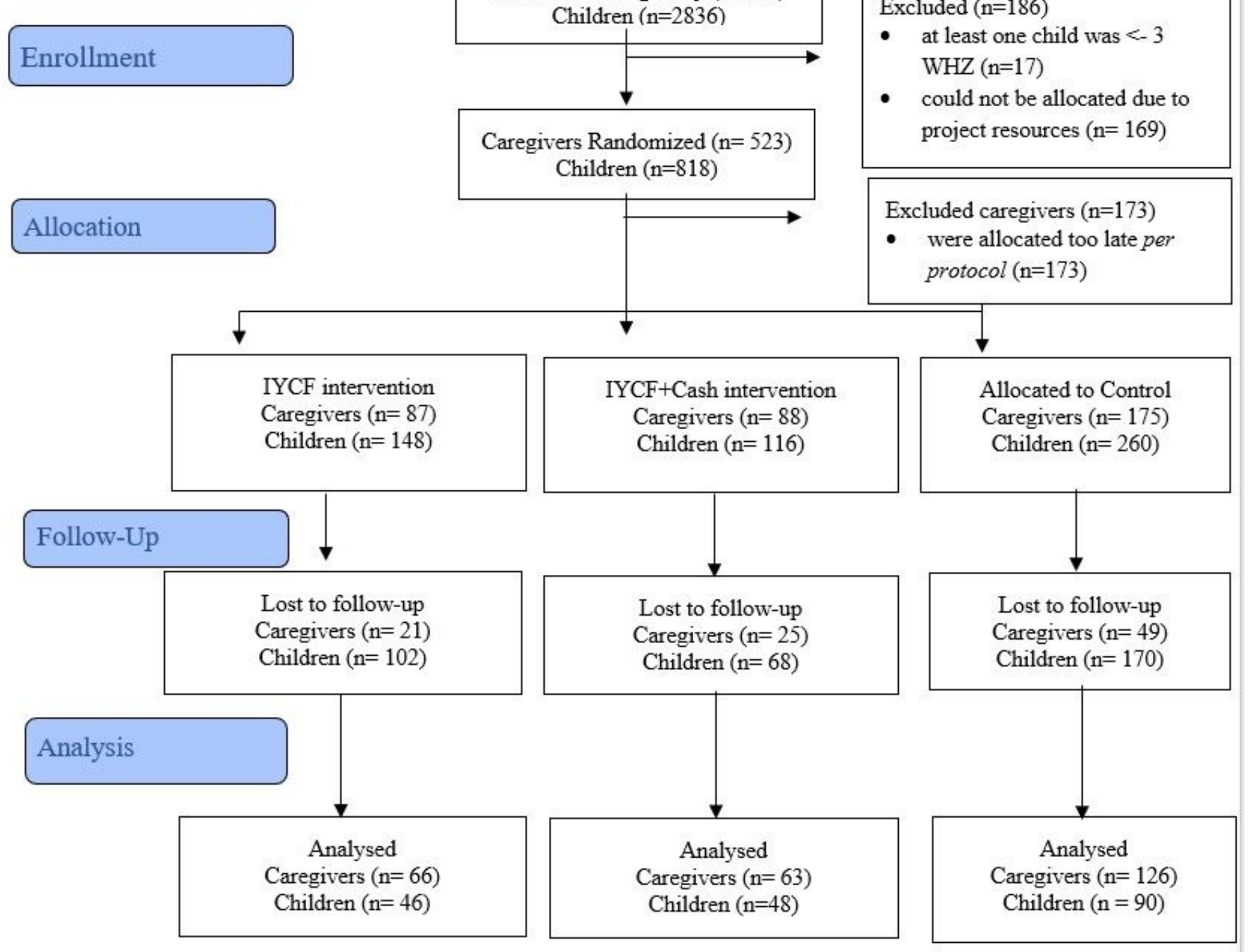

Figure 1

Consort flow chart

\section{Supplementary Files}

This is a list of supplementary files associated with this preprint. Click to download.

- SupplementaryFile1.docx 